\title{
MEWARNAI GAMBAR SEBAGAI SALAH SATU UPAYA UNTUK MENANAMKAN CINTA ALAM dan LINGKUNGAN PADA USIA DINI, DI PAUD BAHAGIA RW-02- KELURAHAN PASEBAN
}

\author{
Sitti Wardiningsih ${ }^{1}$, Siti Sujatini ${ }^{2}$, Euis Puspita Dewi ${ }^{3,}$ \\ Intitut Sains dan Teknologi Nasional, Jakarta Indonesia ${ }^{1}$ \\ Universitas Persada Indonesia ${ }^{2}$, Universitas Persada Indonesia ${ }^{3}$ \\ Email :wardiningsih.sitti@gmail.com; siti_sujatini1@yahoo,euis.puspitadewi@gmail.com
}

\begin{abstract}
ABSTRAK
Permasalahan yang ada di kelurahan Paseban ini adalah daerah permukiman yang kepadatan penduduknya cukup padat dan masalah desa Paseban telah menjadi masalah besar bagi kota-kota besar di Jakarta, termasuk kota Jakarta Pusat. Kegiatan pengabdian Di desa Paseban diadakan melalui kegiatan menggambar pada peserta 30 anak (mendekati usia 3-6 tahun), selain itu dilakukan kegiatan pengolahan sampah melalui penekanan prinsip pemilahan dan lingkaran kehidupan sampah dalam bentuk. Sayangnya, tidak semua warga Jakarta melakukan prinsip-prinsip itu dan berbagai kegiatan lain seperti pelatihan pembuatan asupan nutrisi dan makanan sehat yang terbuat dari singkong yang diadakan oleh PEMBINAAN KESEJAHTERAAN KELUARGA (PKK) yang disebut dengan kelompok Maxi. Maxi, melalui program Pengabdian Masyarakat telah melakukan kegiatan pembuatan di Desa Paseban. Untuk mendidik warga di Paseban, kelompok Maxie mengadakan program lomba menggambar. Program ini merupakan Program Pengabdian Masyarakat yang dilaksanakan oleh Program Studi Arsitektur Fakultas Teknik, colaborasi Universitas Institut Sains dan Teknologi Universitas Persada Indonesia sejak Juni 2013. Metode ini menggunakan metode pendidikan masyarakat dalam bentuk penyuluhan, pelatihan (workshop) masyarakat desa Paseban memiliki tema alam. Realisasi pelaksanaan kegiatan program pengabdian pada masyarakat tersebut menggunakan media kertas gambar yang sudah ada gambar dan siap untuk diwarnai gambar ukuran A3, pinsil warna Crayon. Kegiatan ini diikuti oleh anak didik di lingkungan PAUD BAHAGIA RW-01 yang berjumlah tiga puluh orang (30) anak-anak usia dini. Hasil mewarnai gambar ini terbagi dalam dua katagori dengan kualitas gambar terbaik dan baik.
\end{abstract}

Kata Kunci : Paud, Gambar, Alam lingkungan, Paseban.

\section{ABSTRACT}

The problem of Paseban village has become a big problem for big cities in Jakarta, including the city of Central Jakarta. In Paseban village held activities drawing in the participants 30 childerns (age approach 3-6 years old). To overcome this, a source of waste has to emphasize the sorting principle and waste life circle in the form of. Unfortunately, not all of the Jakarta Citizen do those principles. Beside of activites in there, any another activites checkup nutrition toodler and healthy food made of cassava held by PEMBINAAN KESEJAHTERAAN KELUARGA (PKK). Maxie through the Community Service program has carried out the activities of making in the Paseban Village. In order to educate residents in Paseban, Maxie group held a program using drawing. This program action program which is a Community Service Program implemented by the Architecture Study Program of the Faculty of Engineering, colaborasi Universitas Institut Sains and Teknologi Universitas Persada Indonesia since June 2013. The method used the method of community education in the form of counseling, training (workshop) the community of Paseban village have a theme nature. The process is using a drawing nature, The result obtained is the decreasing 
in having of childrens of PAUD Bahagia in the concern of nature and on produce drawing of best quality, good and sufficient.

Key words : PAUD, Drawing, Nature, Paseban.

\section{PENDAHULUAN}

Pertumbuhan permukiman dan berdirinya bangunan-bangunan yang semakin pesat dan diikuti oleh pertumbuhan tingkat kelahiran yang cukup tinggi. Menyebabkan peningkatan banyaknya jumlah anak-anak usia dini di kampung perkotaan ini. Pada akhirnya masyarakat, khususnya di kawasan permukiman padat melakukan pembiayaran terhadap pembelajaran pengenalan alam dan lingkungannya, mereka hanya memanfaatkan ruang dalam rumah dan pemanfaatan ruang yang tidak pada fungsi yang semestinya. Kondisi dengan keterbatasan tersebut mempengaruhi sikap social budaya mereka dalam memandang dan mengenal alam dan lingkungannya

Pemerintah Provinsi DKI Jakarta secara umum dapat memang sudah dapat menangan bagi kebutuhan pendidikan Usia Dini (PAUD) yang biasanya diselenggarkan oleh Rukun Warga setempat, begitu pula dengan RW02 Kelurahan Paseban juga memiliki PAUD dengan segala keterbatasannya. Manajemen PAUD belum terbangun dengan baik, sementara pertumbuhan anak-anak juga belum bisa ditekan karena tingkat biaya hidup juga semakin meningkat.
Kelurahan Paseban merupakan salah satu bagian wilayah dari Jakarta Pusat, dengan kepadatan akan kegiatan dengan fungsinya sebagai pusat perdagangan, perkantoran, industri, jasa, dan juga permukiman, sehingga perkembangannya cepat sekali terdesak oleh arus pembangunan kota. Pembangunan dan arus urbanisasi yang terjadi membawa dampak terhadap penurunan kualitas lingkungan termasuk pada kawasan permukimannya. Kelurahan Paseban secara umum juga konsen pada perkembangan anak usia dini yang meliputi perkembangan fisik, motorik, kognitif, bahasa, emosi, dan social karena Perkembangan setiap anak berbeda tergantung lingkungan tempat anak tinggal dan pengasuhan orang tua. (Andini, Pupung P, 2012).

Pendidikan anak usia dini (PAUD) adalah jenjang pendidikan sebelum jenjang pendidikan dasar yang merupakan suatu upaya pembinaan yang ditujukan bagi anak-sejak lahir sampai dengan usia enam tahun yang dilakukan melalui pemberian rangsangan pendidikan untuk membantu pertumbuhan dan perkembangan jasmani dan rohani agar anak memiliki kesiapan dalam memasuki pendiidkan lebih lanjut, yang diselenggarakan pada jalur formal, 
non formal, dan informal (Andini, Pupung $P, 2012)$

PAUD adalah penyelenggaraan pendidikan yang menitik beratkan pada peletakan dasar ke arah pertumbuhan dan perkembangan: agama dan moral, fisik motorik, kognitif, bahasa, sosialemosional, dan seni, sesuai dengan keunikan dan tahap-tahap perkembangan sesuai kelompok usia yang dilalui oleh anak usia dini seperti yang tercantum dalam Permendikbud 137 tahun 2014 tentang Standar Nasional PAUD (menggantikan Permendiknas 58 tahun 2009). Ada dua tujuan diselenggarakannya pendidikan anak usia dini, yaitu: Tujuan utama: untuk membentuk anak Indonesia yang berkualitas, yaitu anak yang tumbuh dan berkembang sesuai dengan tingkat perkembangannya sehingga memiliki kesiapan yang optimal di dalam memasuki pendidikan dasar serta mengarungi kehidupan pada masa dewasa. Tujuan penyerta: untuk membantu menyiapkan anak mencapai kesiapan belajar (akademik) di sekolah, sehingga dapat mengurangi usia putus sekolah dan mampu bersaing secara sehat di jenjang pendidikan berikutnya. Rentangan anak usia dini menurut Pasal 28 UU Sisdiknas No.20/2003 ayat 1 adalah 0-6 tahun. Ruang lingkup Pendidikan Anak Usia Dini, di antaranya: bayi (0-1 tahun), balita (2-3 tahun), kelompok bermain (3-6 tahun), dan sekolah dasar kelas awal (6-8 tahun). (Andini,Pupung P -2012).

Bermain sambil mewarnai gambar di khususkan pada anak-anak usia 3 sampai dengan 6 tahun selengarakan untuk meminimalisir dampak kurang sensitifnya terhadap cintai alam lingkungan sekitar maupun diluar lingkungannya. Untuk itu maka perlu dilakukan gerakkan cinta alam dan lingkungan melalui mewarnai gambargambar dilakukan pada PAUD BAHAGIA di RW-02 Kelurahan Paseban.

Manfaat dari kegiatan ini adalah memberikan motivasi dan sensitive terhadap alam dan lingkungan sekitar dan diluar lingkungannya. Kota Administrasi Jakarta Pusat khususnya Kelurahan Paseban melalui program lingkungan sehat ini disenggarakan sejak tahun 2013. Sehingga Kegiatan ini berkelanjutan dan berjalan sampai dengan sekarang di Kelurahan Paseban kegiatan tersebut dapat meningkatkan kualitas pendidikan, pengajaran dan pengetahuan bahkan pengalaman tentang alam dan lingkungan pada Pendidikan Usia Dini (PAUD) dengan sasaran untuk pengajaran, kesehatan dan ekonomi penduduk Masyarakat. Gambar 1 Lokasi Pengabdian Pada Masyarakat dan Persiapan untuk ke Lokasi. 


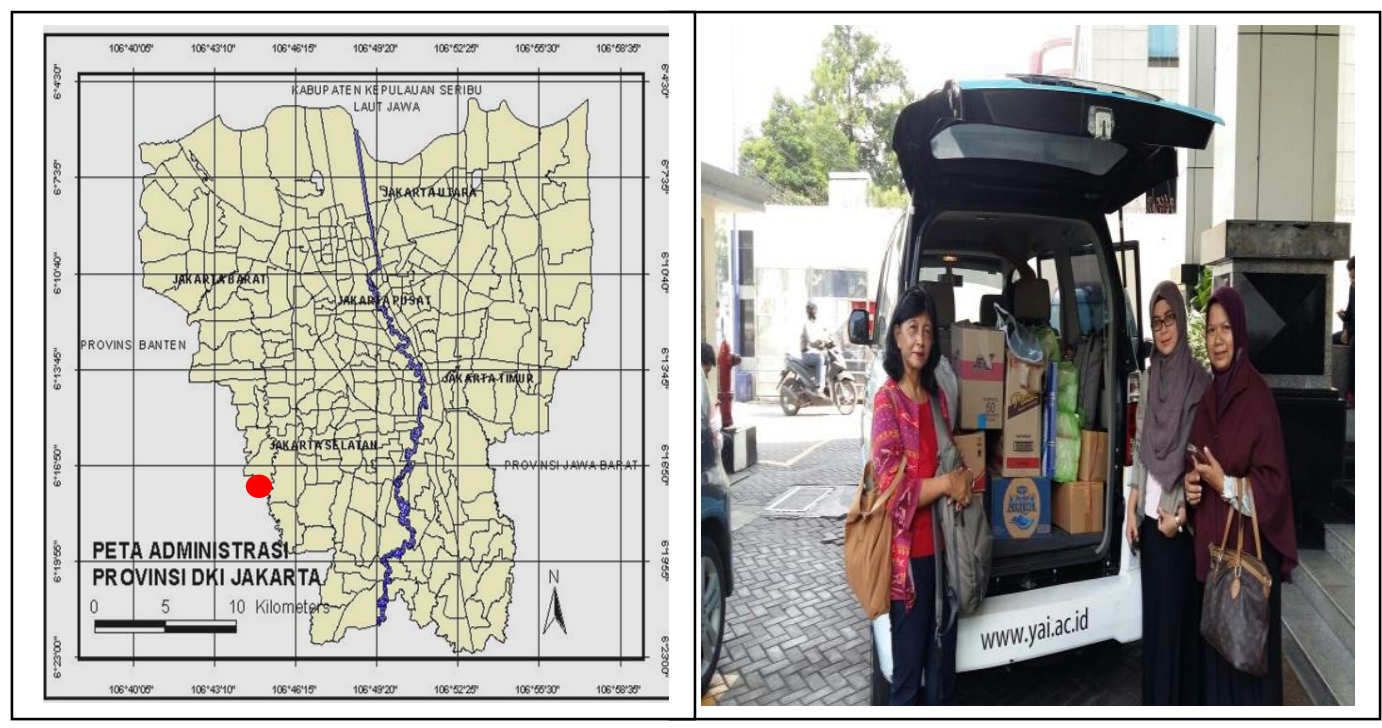

Gambar 1. Lokasi Pengabdian Pada Masyarakat dan Persiapan untuk ke Lokasi.

(Sumber: Penulis 2017)

\section{METODE}

Metode yang dipakai pada Program Pengabdian pada Masyaraka kali ini bertema mumnbuhkan cinta alam dan lingkungan di mulai dari sejak usia dini 3-6 tahun atau pada pendidikan PAUD. Karena pembentukkan karakter dimulai pada usia dini.Pembentukkan tersebut Cara yang dipergunakan adalah dengan workshop mewarnai gambar. Gambar-gambar yang akan diwarnai secara umum tentang alam dan lingkungannya. Kegiatan tersebut dilaksanakan dihalaman kantor Rukun Warga-02. Pada kantor RW tersebut terdapat ruang yang dapat digunakan untuk ruang kelas. Seliuruh kegiatan dilaksanakan di Kelurahan Paseban kota administrasi Jakarta Pusat .

\section{METODE PENDIDIKAN}

Metode pendidikan pengajaran pada usia dini dapat dengan cara mewarnai gambar karena konsep ini adalah salah satu cara untuk Konsep Mengembangkan usia Dini melalui kegiatan Bermain. (Pujiastuti, Yuli 2012), Pendidikan usia dini ini Menurut kami dengan melakukan mewarnai gambar termasuk dalam kata gori bermain, mereka dapat berimajinasi dengan warna-warna yang disukainya. Kegiatan ini bertujuan meningkatkan pemahaman serta kesadaran pada orang tua agar lebih memperhatikan dan mengenalkan alam dan lingkungan sekitar pada anakanaknya yang berada di Kelurahan Paseban khususnya di RW 02, dalam program ini, penulis sebagai nara sumber memberikan pencerahan tentang warna. Penyuluh bersama Narasumber, Penulis dan warga RW-02. Tersaji pada Gambar 2. 


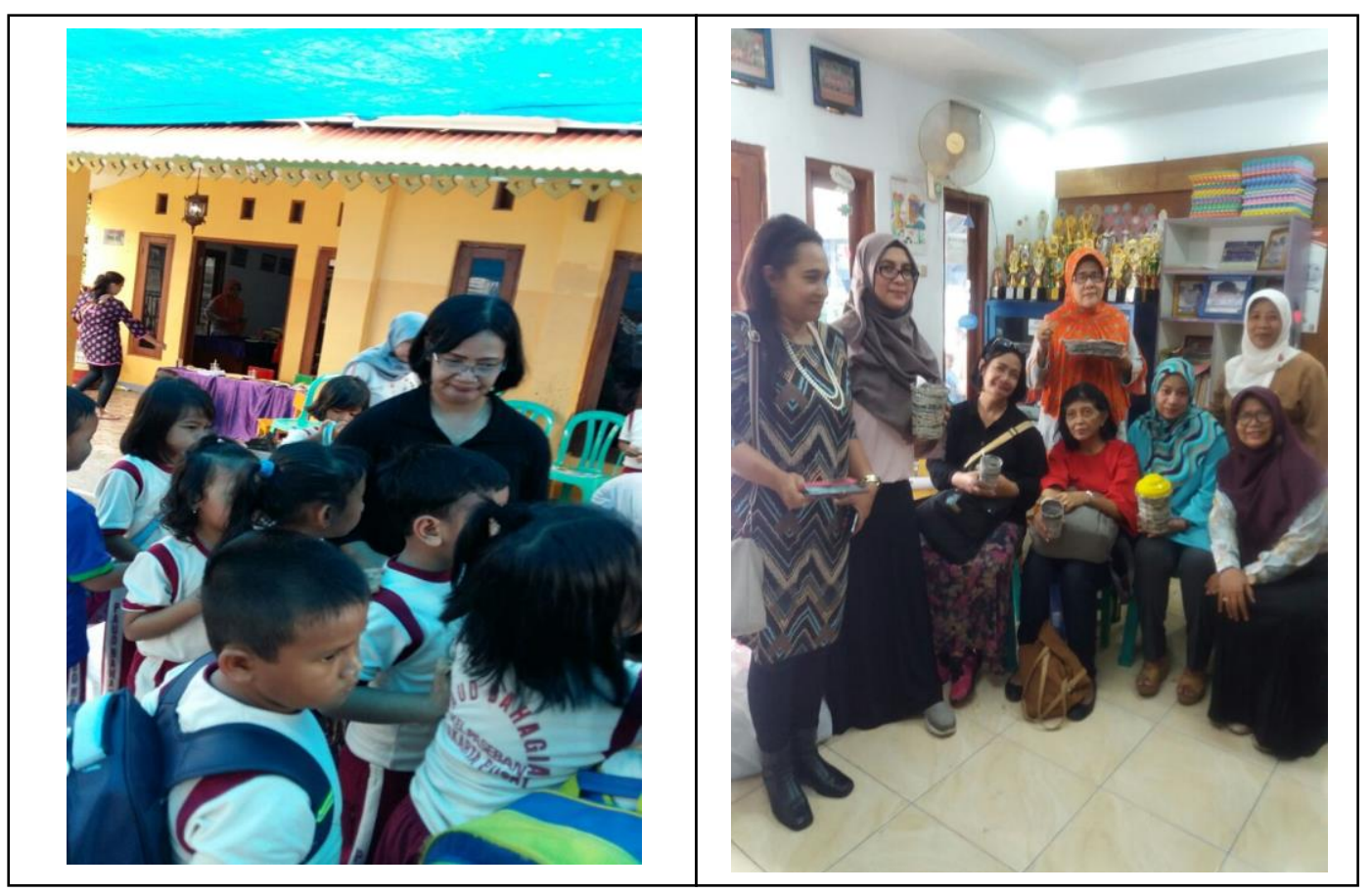

Gambar 2. Pencerahan bersama Narasumber, Penulis dan Warga

(Sumber : Penulis, 2017).

METODE MEWARNAI

(WORKSHOP) DAN PENYULUHAN LINGKUNGAN SEHAT.

Metode mewarnai gambar termasuk dalam katagori pelatihan (workshop) adalah kegiatan yang disertai dengan demonstrasi atau percontohan untuk menghasilkan keterampilan tertentu. Pada program Pengabdian pada Masyarakat ini, dilaksanakan pada tanggal 12 Mei 2017 di kantor RW-02 yang dihadiri oleh panitia, warga RW 02 , serta utusan Kelurahan Paseban Jakarta Pusat. Dalam kegiatan ini penulis sebagai nara sumber yang menjelaskan tentang mewarnai yang baik dan pemilihan warna.

Pencerahan tentang cara mewarnai yang baik, pemilihan warna hal ini bertujuan untuk memberikan pembekalan pada anak-anak peserta mewarnai gambar di Kelurahan Paseban khususnya di RW 02 yang dapat mengedukasi anak-anak usia dini yang tergabung dalam PAUD tersebut mengenai cara mewarnai yang baik dan memilih warna sesuai dengan keinginan nya sendiri, waktu workshop mewarnai gambar dilakukan selama seratus delapan puluh menit (180). Seluruh rangkaian kegiatan (workshop) mewarnai gambar ini adalah kegiatan dari program pengabdian masyarakat yang diawali kata sambutan, pembekalan materi atau pencerahan dari narasumber, penyuluhan lingkungan sehat dan pembagian kertas bergambar berukuran A3 serta Crayon warna pada semua peserta. Gambar 3. 


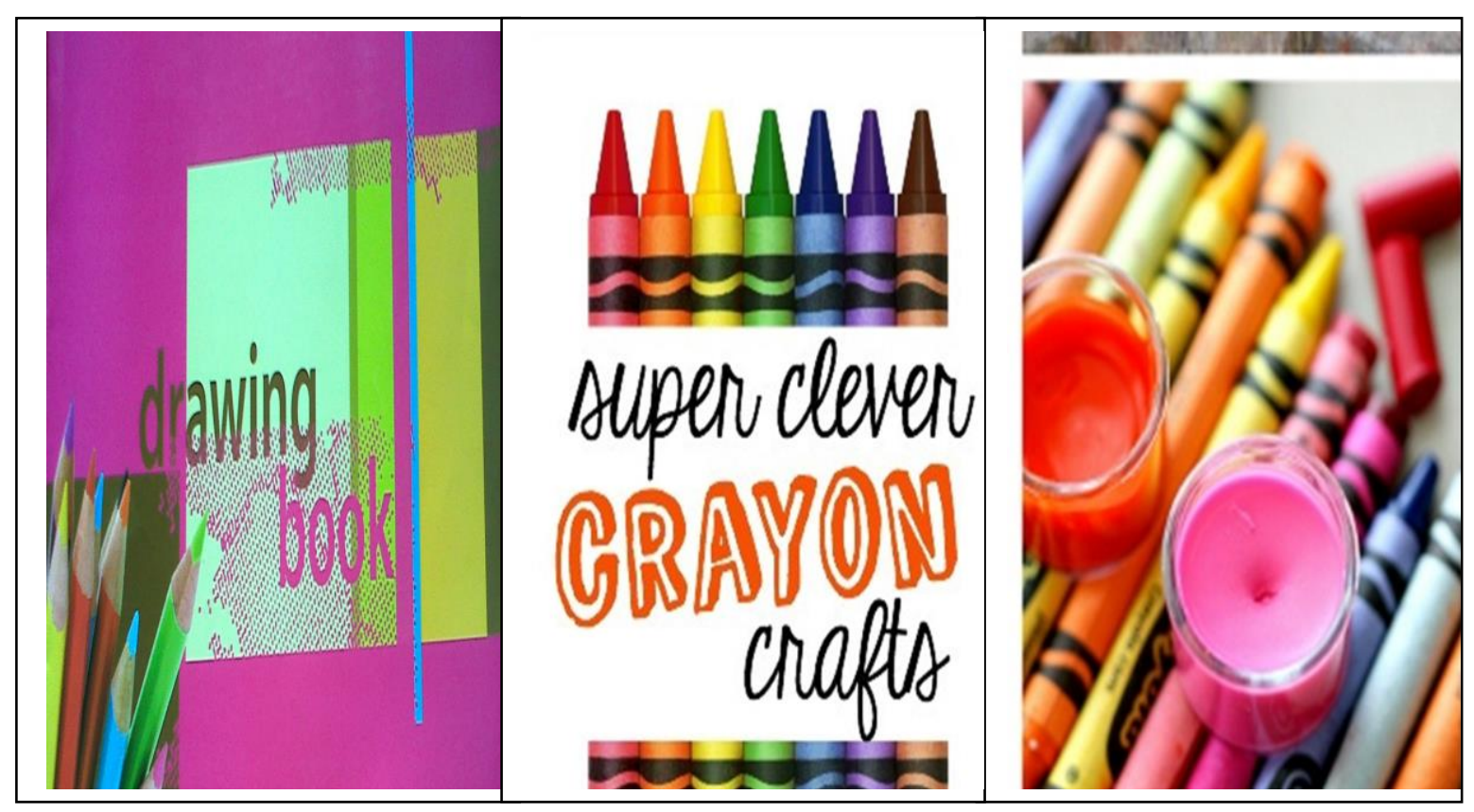

Gambar 3. Alat Untuk mewarnai Kertas gambar A3 dan Crayon

(Sumber : Penulis, 2017).

Setelah selesai diadakan pencerahan oleh narasumber dan penulis mengarahkan kepada anak-anak peserta di kelurahan Paseban khususnya di warga RW-02 untuk melakukan praktek sendiri dalam mewarnai gambar-gambar dengan Crayon yang sudah dibagikan pada seluruh peserta. Pengabdian Pada Masyarakat kali ini mengambil Tema Mencintai Lingkungan " di Rw - 02 dengan "Tema Mencintai Lingkungan “ yang dilaksanakan pada Tanggal 12 Mei 2017.

Kesehatan Lingkungan adalah suatu ilmu dan seni dalam mencapai kesimbangan antara lingkungan dan manusia. Prilaku hidup bersih dan sehat adalah upaya untuk memberikan pengalaman belajar atau menciptakan informasi dari suatu kondisi bagi perorangan, keluarga, kelompok dan masyarakat.

Lokasi tempat pelaksanaan mewarnai gambar ini bertempat dikantor Rukun Tetangga (RW) 02 yang juga menjadi lokasi sekolah PAUD BAHAGIA di Kelurahan Salemba, Perlu kami tambahkan babwa pada hari dan tanggal yang sama terdapat kegiatan lain yaitu posyandu yang diselenggarakan oleh ibu-ibu Pembina Kesejahteraan Keluarga (PKK) RW-02 Kelurahan Paseban melakukan penyuluhan tentang gizi untuk anak balita serta membuat kuekue dengan bahan singkong. Lokasi pelaksanaan Kegiatan Pengabdian Masyarakat seperti pada Gambar 4. 


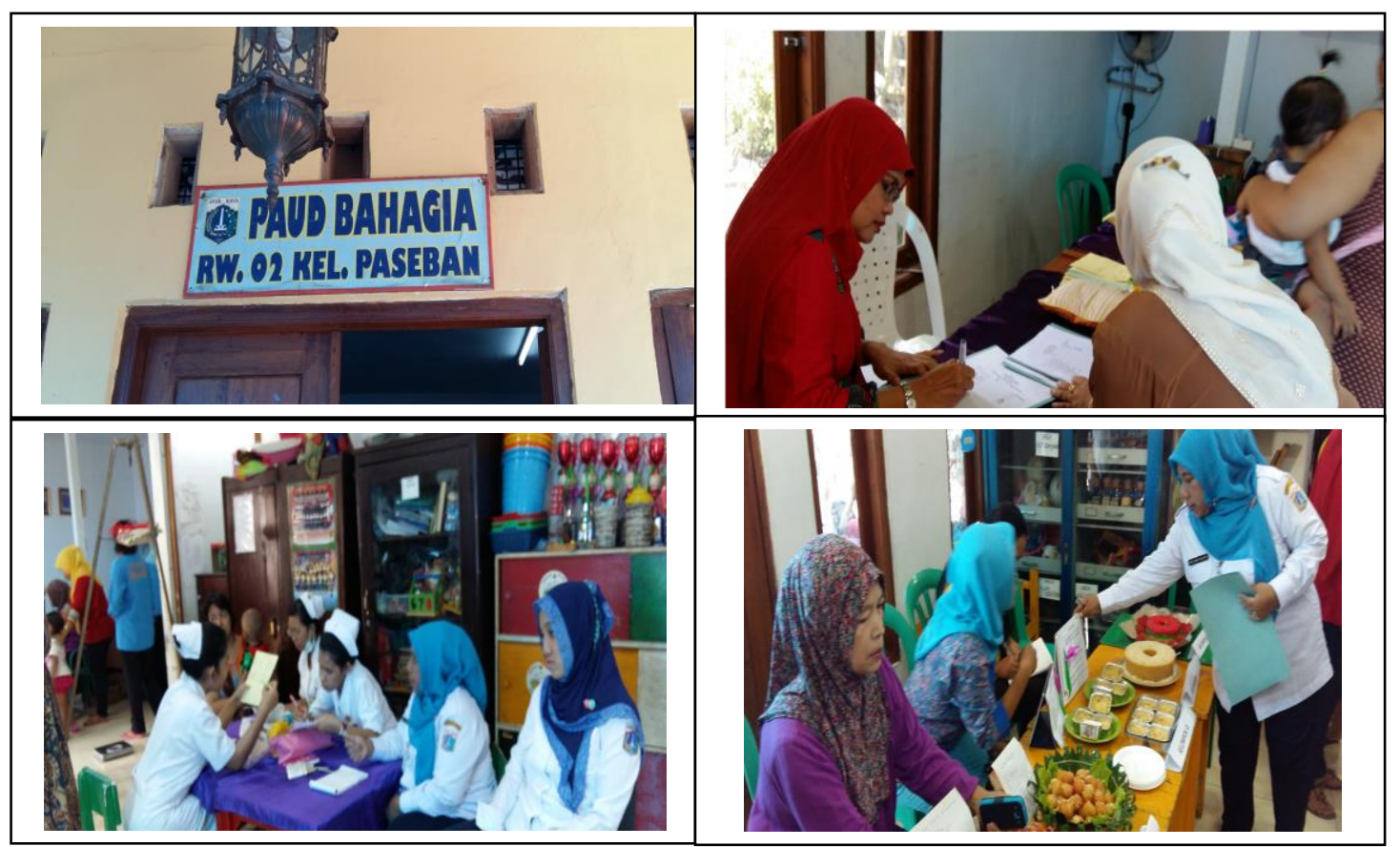

Gambar 4. Kegiatan yang bersamaan dengan mewarnai gambar pada kantor RW-02 di PAUD BAHAGIA, Kelurahan Paseban.

(Sumber: Penulis 2017).

\section{HASIL DAN PEMBAHASAN}

Program Lingkungan Sehat merupakan Program Pengabdian pada Masyarakat yang mulai dilaksanakan oleh Institut Sains dan Teknologi Nasional Program Studi Arsitektur Lanskap dan Program Studi Arsitektur Fakultas Teknik Universitas Persada Indonesia (UPI YAI) lintas Program studi sejak bulan Mei 2013 dalam program Lingkungan Sehat penghijauan dan penyuluhan di Kelurahan Paseban, Jakarta Pusat.

Menurut Ditjen DIKMAS Pendidikan Usia dini memiliki fungsi utama menembangkan semua aspek perkembangan anak, meliputi kognitif, bahasa, fisik (motorik kasar dan halus), Sasaran utama secara fungsi dari pendidikan PAUD ini: 1. Memberikan pengasuhan dan pembimbingan yang memungkinkan anak usia dini tumbuh dan berkembang sesuai dengan usia dan potensinya, 2. Mengidentifikasi penyimpanganyang mungkin terjadi, sehingga jika terjadi penyimpangan dapat dilakukan intervensi dini. 3 . Menyediakan pengalaman yang beranekaragam dan mengasyikkan bagi anak usia dini, yang memungkinkan mereka mengembangkan potensi dalam berbagai bidang sehingga siap untuk mengikuti pendidikanpada jenjang sekolah dasar (SD).

Sedangkan menurut UU No 23 / 1992 Tentang kesehatan "Keadaan sejahtera dari badan, jiwa dan sosial yang memungkinkan setiap orang hidup 
produktif secara sosial dan ekonomis." Pengertian Lingkungan Menurut A.L. Slamet Riyadi (1976) adalah "Tempat pemukiman dengan segala sesuatunya dimana organismenya hidup beserta segala keadaan dan kondisi yang secara langsung maupun tidak dapat diduga ikut mempengaruhi tingkat kehidupan maupun kesehatan dari organisme itu."

Gizi adalah susunan makanan sehari-hari yang mengandung zat-zat gizi dalam jenis dan jumlah yang sesuai dengan kebutuhan tubuh, dengan memerhatikan prinsip keanekaragaman atau variasi makanan, aktivitas fisik, kebersihan, dan berat badan (BB) ideal.Pengertian sehat menurut $\mathrm{WHO}$ adalah "Keadaan yg meliputi kesehatan fisik, mental, dan sosial yg tidak hanya berarti suatu keadaan yg bebas dari penyakit dan kecacatan."Sedangkan menurut UU No 23 / 1992 Tentang kesehatan "Keadaan sejahtera dari badan, jiwa dan sosial yang memungkinkan setiap orang hidup produktif secara sosial dan ekonomis."

Pengertian Kesehatan Lingkungan Menurut World Health Organisation (WHO) pengertian Kesehatan Lingkungan : Those aspects of human health and disease that are determined by factors in the environment. It also refers to the theory and practice of assessing and controlling factors in the environment that can potentially affect health. Atau bila disimpulkan "Suatu keseimbangan ekologi yang harus ada antara manusia dan lingkungan agar dapat menjamin keadaan sehat dari manusia. Pengertian lingkungan sehat adalah lingkungan yang mendukung terciptanya individu warga yang sehat serta masyarakat yang sehat.

$$
\text { Program Pengabdian pada }
$$

Masyarakat kali ini mengedepankan pendidikan dan pembelajaran dengan mewarnai gambar yang bertemakan "Tema Mencintai Alam dan Lingkungan" adalah kelanjutan dari program sebelumnya, program berkelanjutan dari program Kesehatan Lingkungan, di Kelurahan Paseban, Jakarta Pusat. Untuk kegiatan mewarnai gambar ini dilaksanakan pada tanggal 12 Mei 2017 dengan tujuan memningkatkan rasa kagum di luar lingkungannya yang pada akhirnya mereka dapat bersyukur kagum terhadap ciptaan Tuhan dan timbul rasa untuk menyayanginya. Mewarnai gambar ini berfungsi untuk memperbaiki menggali bakat dan kemampuan anak anak sejak dini Ruang lingkup Pendidikan Anak Usia Dini, di antaranya: bayi (0-1 tahun), balita (2-3 tahun), kelompok bermain (3-6 tahun), dan sekolah dasar kelas awal (6-8 tahun).

PAUD BAHAGIA berada di Kelurahan Salemba, Kecamatan Senen Jakarta Pusat di RW-02, terdapat kegiatan yang bersamaan yaitu : mewarnai gambar, penyuluhan tentang kesehatan lingkungan serta pemeriksaan gizi balita, maka kami kelompok maxie dari lintas universitas dan lintas 
membentuk panitia program kegiatan Pengabdian Pada Masyarakat. Kemudian melaksanakannya dan mesosialisasikan dalam Program lingkungan sehat untuk warga masyarakat dilingkungan ini (RW-02). Kelurahan Salemba Kecamatan Senen. Kegiatan ini merupakan Program Pengabdian pada Masyarakat yang diselengarakan dan dilaksanakan oleh Program Studi Arsitektur lanskap, Program Studi, Arsitektur, Program Studi Teknik Sipil dan Program Studi Teknik Industri Fakultas Teknik Universitas Persada Indonesia dan Institut Sains dan Teknologi Nasional. diawali dengan sosialisasi yang lingkungan yang sehat diadakan di Ruang kelas PAUD BAHAGIA, yang dihadiri oleh perwakilan warga di RW - 02 beserta penulis dan narasumber pada tanggal 12 Mei 2017.

Program kegiatan pengabdian pada masyarakat kali ini terbagi dalam tiga (3) kegiatan yang meliputi: Mewarnai gambar yang dilaksanakan selama seratus delapan puluh menit (180 menit) yang dikuti oleh anak didik PAUD sejumlah tiga puluh orang anak (30 Orang). Untuk kertas gambar dan pinsil Crayon disediakan oleh panitia. Tepat pukul 10.00 wib dimulailah acara untuk mewarnai gambar yang diikuti oleh anakanak usia dini yang tergabung dalam PAUD BAHAGIA ini.

Kegiatan mewarnai gambar diikuti anak-anak PAUD BAHAGIA RW - 02 Kelurahan Paseban sejumlah 20 orang dari PAUD BAHAGIA sejumlah 10 orang. Diluar PAUD BAHAGIA. Dalam Kegiatan ini yang diizinkan untuk ikut adalah kelompok usia 3 sampai dengan 6 tahun. Gambar 5. Kegiatan pelaksanaan Mewarnai gambar dengan menggunakan Gambar kertas A3 dan Crayon. Kegiatan mewarnai dan hasil akhir tersaji pada gambar 5 .

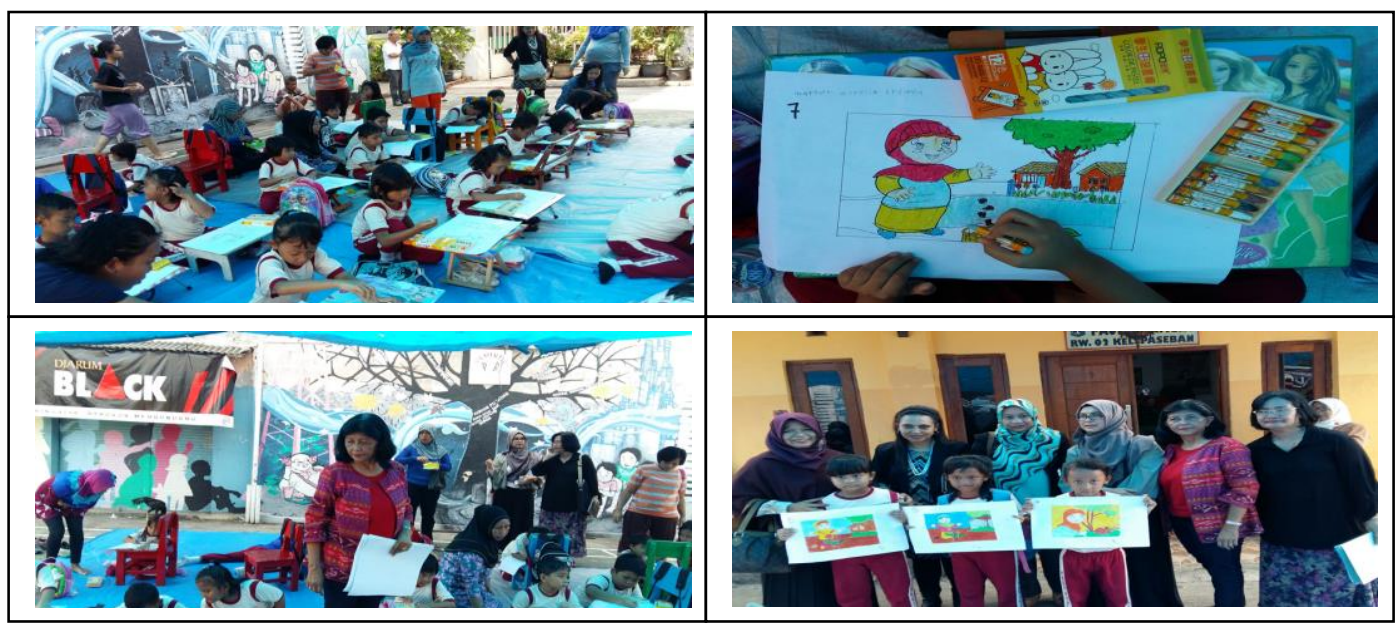

Gambar 5. Mewarnai gambar dengan menggunakan Gambar A3 dengan Crayon (Sumber : Penulis, 2017) 
Dalam pengabdian Masyrakat kali juga dilakukan Kegiatan gizi sehat untuk anak,dengan mengandeng puskesmas., dalam kegiatan meliputi pemeriksaan, penimbangan berat badan oleh tenaga medis dari Puskesmas kecamatan Senen. Kegiatan anak balita tersaji pada gambar 6 .

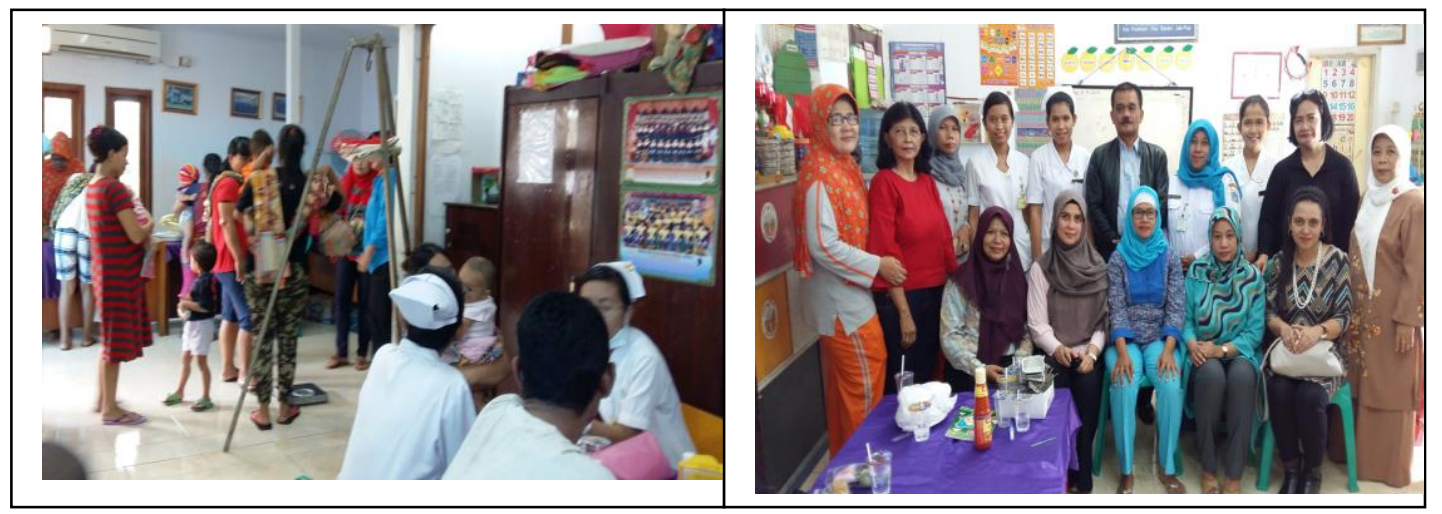

Gambar 6 Kegiatan penyuluhan gizi untuk anak tersaji pada gambar (Sumber : Penulis 2017).

Penyuluhan dan workshop (pembuatan kue-kue tersebut dilakukan dirumah warga masing-masing) dengan nara sumber DR.Ir. Fitriyani, MT, hasil dari penyuluhan, para peserta diminta untuk membuat kue-kue dengan bahan dasar singkong dengan memberikan modal pada peserta sebesar Rp.20.000,( dua puluh ribu rupiah). DR. Ir. Fitriyani, MT dan Hasil pembuatan kue singkong tersaji pada Gambar 7.

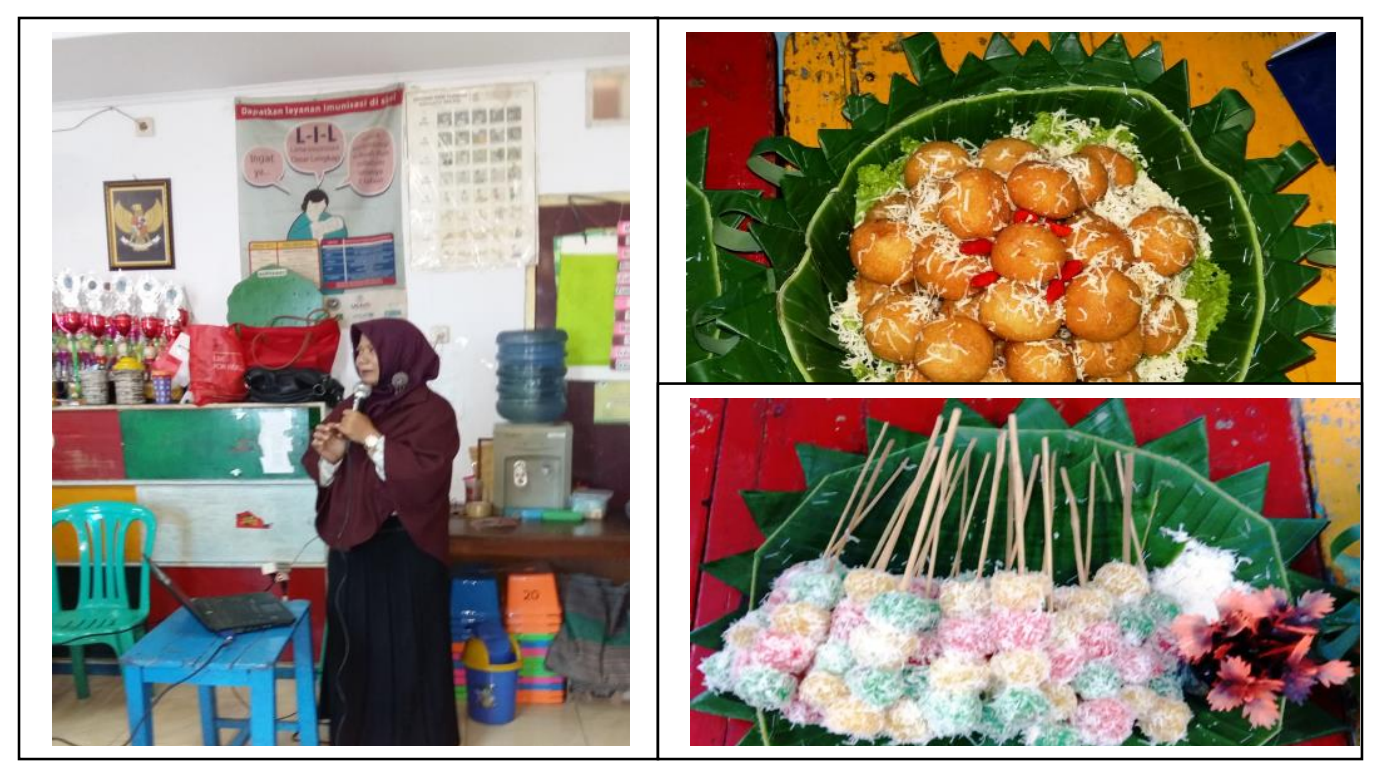

Gambar 7 : Narasumber DR. Ir.Fitriayani, MT dan Makanan terbuat dari Singkong (Sumber: Penulis 2017). 
Pada tahap akhir dari kegiatan Pengabdian pada Masyarakat ini ditutup dengan doa yang dipimpim oleh bapak RW- Pak Yono, dengan harapan ditahun yang akan datang dapat terjalin lagi dan dalam acara kegiatan yang berbeda. Foto bersama dengan peserta mewarnai terdiri dari anak-anak PAUD BAHAGIA serta panitia, guru-guru, tersaji pada gambar 8

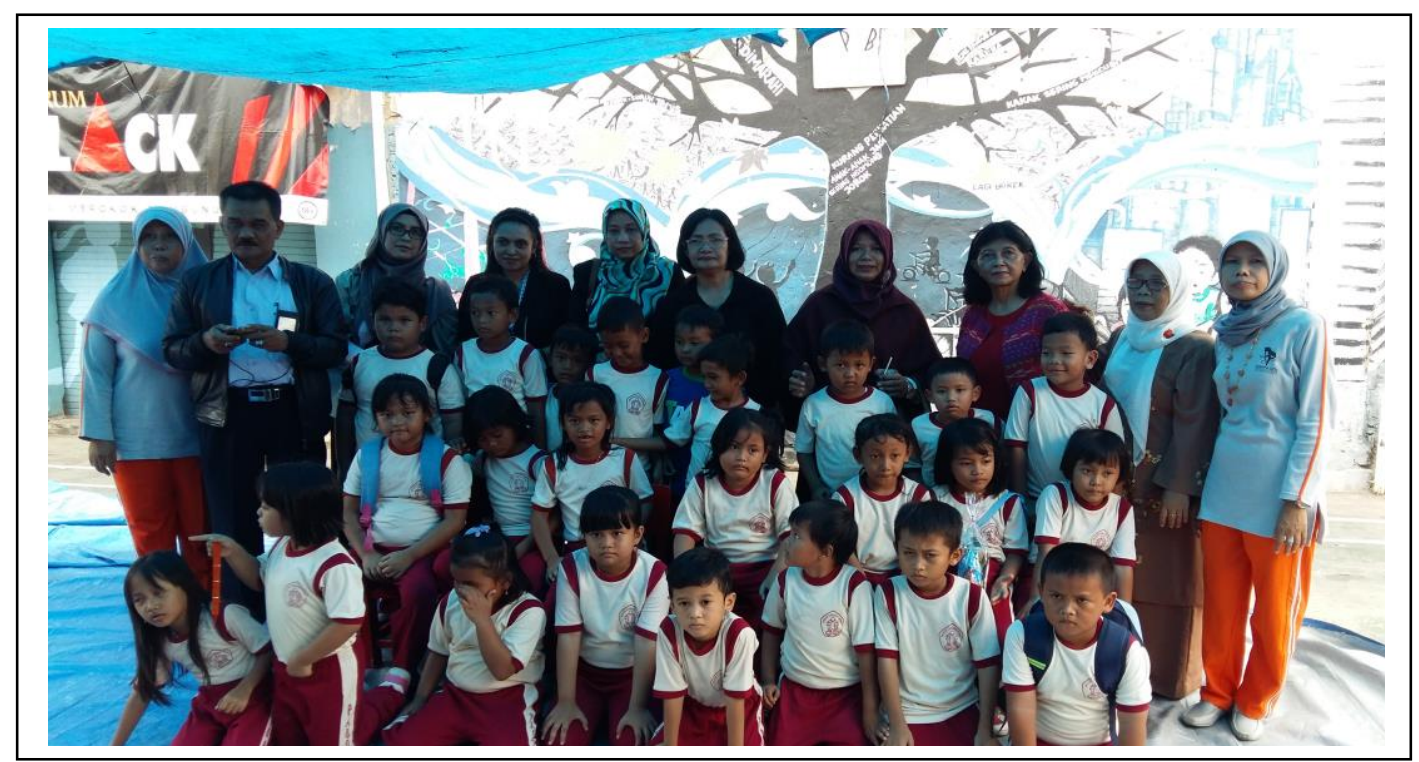

Gambar 8: Pak RW dan Keluarga PAUD BAHAGIA, Panitia serta guru -guru

\section{SIMPULAN}

Program Pengabdian Masyarakat dengan Tema Mencintai Lingkungan dengan cara Melalui Kegiatan mewarnai gambar, penyuluhan lingkungan dan gizi sehat 2017 di beberapa RW-02 Kelurahan Paseban Kecamatan Senen.

Program ini terdiri dari beberapa rangkaian acara diantaranya proses sosialisasi, workshop, lingkungan sehat dan membuat penganan sehat dengan biaya murah menghasilakn makanan yang terjamin kebersihan dan kesehatannya, pemberian uang sebagai modal sebesar duapuluh ribu serta dilakukan semacam penilaian rasa, penataan penyajian, semua kegiatan memasak dipraktikkan sendiri di rumahnya. Warga masyarakat khususnya RW-02 sangat antusias dan merasa program ini sangat bermanfaat karena dengan mendapat edukasi yang cukup mengenai gizi dan lingkungan sehat meningkatkan hasil perekonomian warga setempat.

Semoga Program Pengabdian Masyarakat Yang Berjudul Mewarnai Gambar Sebagai Salah Satu Upaya Untuk Menanamkan Cinta Alam Dan Lingkungan Pada Usia Dini, Di Paud Bahagia RW-02 Kelurahan Paseban dapat berkelanjutan di tahun-tahun berikutnya. 


\section{UCAPAN TERIMA KASIH}

Puji dan syukur kami panjatkan ke hadirat Tuhan Yang Maha Esa, karena berkat rahmat dan karunia-Nya kami telah dapat menyelesaikan seluruh proses penyusunan Laporan Program Pengabdian Pada Masyarakat Lintas yaitu: Kampus Institut Sains dan Teknologi Nasional, Fakultas Teknik Sipil dan Perencanaan, Program Studi Arsitektur Lanskap dengan dengan Universitas Persada Fakultas Teknik lintas Prodi (Teknik Arsitektur, Teknik Sipil, Teknik Industri, dan Teknik Informatika) di tahun 2017 ini yang bertemakan " Mencintai Alam dan Lingkungan" dengan cara melakukan mewarnai gambar yang Menggunakan media gambar Melalui Kegiatan Mewarnai Gambar yang bertemakan Alam dan Lingkungannya.

Terimakasih sebesar-besarnya tidak lupa kami ucapkan ucapkan kepada :

1. Kepada rekan rekan teman- dosen yang berpartisipasi untuk sumbangan tenaga, pikiran dan dana sehingga Program Pengabdian Pada Masyarakat yang berjudul Mencintai Alam dan Lingkungan"'.

2. Bapak Pak Yono sebagai RW yang tyelam memberikan izin untuk melakukan kegiatan Pengabdian Pada Masyarakat dilingkungan RW-02.
3. Bapak Hermansyah, $\mathrm{SH}$ selaku utusan Lurah di Kelurahan Paseban yang telah memberikan dukungan demi kelancaran kegiatan Program Pengabdian Pada Masyarakat ini

4. Ibu DR.Ir. Stiadamayanti, MSc sebagai Dekan Fakultas Teknik ISTN

5. Bapak Ir. Sukrisno, MSI sebagai Dekan Fakultas Teknik Universitas Persada Indonesia.

6. Bapak Ir.Daisy Radnawati, MSi, sebagai Ketua Program Studi Arsitektur Lanskap ISTN

7. Terimakasih atas kerjasamanya.

8. Rekan Dosen lintas kampus dan lintas Program Studi pada kedua kampus yang tersebut diatas partisipasi untuk mendukung Program ini sudah dapat berjalan lancar dan sukses.

9. Khususnya Ketua RW 02 dan semua warga Kelurahan Paseban, Kecamatan Senen Jakarta Pusat yang sudah meluangkan waktu dan tenaganya untuk mengikuti Program ini.

Semoga artikel ini dapat bermanfaat bagi kita semua khususnya di lingkungan Universitas di luar sana.

\section{REFERENSI}

Ardini, P. P. (2012). Pengaruh dongeng dan komunikasi terhadap perkembangan moral anak usia 
Volume 1, Nomor 1, Tahun 2019 Hal 37 - 49

7-8 tahun. Jurnal Pendidikan

Anak, 1(1).

Permendikbud 137 tahun 2014 tentang

Standar Nasional PAUD

(menggantikan Permendiknas 58

tahun 2009)

http://www.tribunnews.com

Pujiastuty, Yuli, (2012). Mengembangkan

Konsep Dini Melalui Kegiatan

Bermain. Jurnal Pendidikan Anak, $6(2)$.

Rahmahadi, Aryani, (2012) Pengaruh

Strategi Pembelajaran Dan Status

Sosial Elemen Orang Tua

Terhadap Krativitas. Jurnal

Pendidikan Anak, 6(2).

Usman, (2011) Tugas Tugas

Perkembangan Anak Usia Dini, Jurnal Pendidikan Anak, 5(2).

http://www.indonesian

publichealth.com/pengertian-

kesehatan-lingkungan. Unduh 14

Maret 2019

https://www.samishare.com/pengertian-

lingkungan-sehat-1016, Unduh 15

Maret 2019. 